\title{
The United Kingdom transient ischaemic attack (UK-TIA) aspirin trial: final results
}

\author{
UK-TIA study group
}

\begin{abstract}
From 1979-85, 2435 patients with a transient ischaemic attack or minor ischaemic stroke were randomly allocated to receive long term "blind" treatment with aspirin $600 \mathrm{mg}$ twice daily $(\mathbf{n}=815)$, aspirin $300 \mathrm{mg}$ once daily $(n=806)$ or placebo $(n=814)$. No patient was lost to follow up. The "intention to treat" comparison included all the serious vascular events and deaths which occurred before the end of the follow up period on 30 September 1986. There was no difference in efficacy between the $300 \mathrm{mg}$ and $1200 \mathrm{mg}$ daily doses of aspirin, but the lower dose was undoubtedly less gastrotoxic. Also, there was no definite difference in the response of males and females to aspirin. The odds of suffering a major stroke, myocardial infarction or vascular death were $15 \%$ less in the combined aspirin groups compared with the placebo group (95\% confidence interval $29 \%$ reduction to $3 \%$ increase in odds) which is compatible with the continuing overview of all the similar trials of antiplatelet drugs where the relative reduction in odds was $25 \%$. There was no statistically significant reduction in the likelihood of either disabling major stroke and vascular death or vascular death occurring.
\end{abstract}

In 1988 we published the interim results of the United Kingdom transient ischaemic attack (UK-TIA) trial of long-term treatment with aspirin in 2435 patients with a transient ischaemic attack or minor ischaemic stroke. ${ }^{1}$ The data were incorporated into the first phase of an overview of all similar trials ${ }^{2}$ from which it was clear that no antiplatelet drug, or combination of drugs, was definitely more effective in reducing the risk of serious vascular events than aspirin, $300 \mathrm{mg}$ daily. We now report the final result of the trial which included all the major events in all the randomised patients. These data supersede the interim results, are available for the second phase of the Antiplatelet Trialists' Collaboration, and provide the only direct, randomised comparison of $300 \mathrm{mg}$ with $1200 \mathrm{mg}$ aspirin taken daily on a long-term basis.

\section{Patients and methods \\ Patients}

Between 25 July 1979 and 8 October 1985, 57 consultant neurologists (about one third of the total in the United Kingdom and Eire) working in 33 centres, recruited patients they thought had had a recent transient ischaemic attack (TIA) or minor ischaemic stroke (definitions of events are given below). Although CT was not widely available at the time, the vast majority of such minor strokes were presumably ischaemic and not due to primary intracerebral haemorrhage. Our intention was to avoid randomising patients less than 40 years old; those whose last cerebrovascular event had occurred more than three months earlier; those who had previously experienced a disabling major stroke; those whose attacks were definitely due to something other than arterial thromboembolism (migraine, hypoglycaemia, anaemia, polycythaemia rubra vera, cardiac arrhythmia, arteritis), but to include patients with potential cardiac sources of embolism who were not anticoagulated. We also excluded patients that were likely to experience adverse effects from aspirin-that is, previous allergy or intolerance, previous abnormal bleeding, alcoholism, chronic renal failure, peptic ulceration in the previous three years. Finally, we excluded patients if the trial analysis was likely to be confounded by aspirin taken from 90 days or more pre-randomisation, if they needed regular aspirin (or any other antihaemostatic medication), had had a myocardial infarction within three months before randomisation, might have difficulty with follow up, might comply poorly, or had severe intercurrent non vascular disease.

\section{Randomisation and trial medication}

Eligible patients were randomised by telephoning the Clinical Trial Service Unit in Oxford. A two letter code was allocated which matched coded medication packs held by the local hospital pharmacists. Each four month patient pack contained 20 one week foils of 28 tablets; two tablets were to be taken in the morning and two in the evening (preferably with or after food) and each pair of tablets was specifically labelled by the day of the week and whether it was to be taken in the morning or evening. At first, aspirin and lactose placebo were supplied by Evans Medical Ltd/ Glaxo and contained the following excipients: maize starch, ascorbic acid, sodium saccharin, organe $84232 / \mathrm{B}$, magnesium stearate, purified talc, citric and tartaric acids. The orange flavour disguised the taste of aspirin even if the tablets were chewed rather than swallowed whole as instructed. To further increase the blind nature of the study, the tablets were at first coated with hydroxypropyl-methyl- 
cellulose and ethylcellulose film. In 1982 Eli Lilly started supplying enteric coated aspirin and lactose placebo for those patients unable to tolerate the plain trial tablets; the excipients consisted of starch, povidone, amberlite XD88, microcystalline cellulose granular 102 and magnesium stearate. In 1984 the plain tablet manufacture was taken over by Beecham Products and they were no longer film coated. Patients who were randomised to "high dose" aspirin received two $300 \mathrm{mg}$ tablets twice daily, those randomised to "low dose" aspirin received two $150 \mathrm{mg}$ aspirin tablets in the morning and the two evening tablets were placebo, and those randomised to "placebo" received two placebo tablets twice daily.

Each four month patient pack contained a leaflet giving information on when to take the medication, if tablets were missed not to take them the following day but to leave them in the packet, and to avoid non trial aspirin. It also included a container for urine collection for compliance testing (see below). Patients who complained of indigestion were advised to omit the evening pair of tablets. If they still complained of indigestion, they were told to take just one of the two morning tablets. If these stepdowns failed they were advised to transfer to enteric coated trial medication, four tablets a day and then-if necessary-to try reducing to one morning tablet daily. In this way we maintained as many patients as possible on, or as near to, their allocated treatment for as long as possible. Even if medication had to be stopped this was not necessarily permanent. Even if it was, the patients continued on follow up.

\section{Follow up}

Patients were seen every four months until after the scheduled end of the trial (30 September 1986), their prior death or emigration. If they could not, or would not, come to the neurological clinics, follow up was continued by postal or telephone contact with their general practitioners. In addition, each patient was flagged with the Office of Population Censuses and Surveys so that we received a death certificate in the event of their death. All the surviving patients were reviewed after the 30 September 1986. This was to ensure that all important events had been recorded and to inform the patients of the interim trial results (but not of their own treatment as the collaborators were still "blind" at that time).

\section{Analysis of major events}

In 1979 we originally envisaged the analysis would be of time to "non fatal major stroke, non fatal myocardial infarction, vascular death or non vascular death" taken as a composite event in a conventional log rank survival analysis. ${ }^{3}$ In 1984 , without reference to the trial data, we decided that the analysis should include survival free of disabling stroke, whilst definitely non-vascular deaths should be censored. This was because we were concerned that aspirin, by virtue of its anti- haemostatic effect, might cause haemorrhagic strokes. This possibility was not only biologically plausible, but had been suggested in a case control study by Skegg and Doll. ${ }^{4}$ Since haemorrhagic strokes tend to be more severe than cerebral infarcts, an analysis which counted "all strokes" might be misleading if aspirin prevented a large number of mild cerebral infarcts but caused a small number of more severe cerebral haemorrhages. Also, since aspirin was $a$ priori unlikely to influence non-vascular deaths (which has since been confirmed in the overview of allsimilar trials) ${ }^{2}$ we wished to increase the sensitivity of our analysis by excluding them. We also considered that the most sensitive analysis to assess aspirin should be based on time to "major stroke, myocardial infarction or vascular death", as this composite event gives the greatest number of events likely to respond to an antithrombotic drug; we defined this at the main outcome of interest. Various other analyses of fatal and non-fatal events (for definitions see below) were conducted separately and in various relevant combinations. The combination "all stroke/myocardial infarction/vascular death" included minor as well as major strokes to be comparable with the continuing overview of all similar trials, not all of which distinguished minor from major strokes, nor disabling from nondisabling strokes. ${ }^{2}$ Unless otherwise stated, all analyses were based on the "intention to treat" principle and included all events occurring in all patients until the 30 September 1986 inclusive, or until the patients' prior death or emigration, whether or not they were taking trial medication at the time of the event.

For all reported major events (major stroke, myocardial infarction and death) the hospital medical records were reviewed, (as were the general practitioner's medical notes, if required) by $\mathrm{CW}$ who was blind to treatment allocation throughout the trial). A brief summary was made of the clinical, investigation and postmortem examination details (if performed). Death certificate diagnoses were only accepted if no other information was available. This summary was sent to the relevant collaborating neurologist for checking and then to the clinical audit committee. All the events were again reviewed by this committee after the end of the trial and a final decision made on how they should be coded, again blind to treatment allocation.

\section{Adverse effects and compliance}

At each four monthly follow up visit the patients were asked about any adverse effects and if they had been taking the trial medication regularly, irregularly or not at all. If the trial medication was irregular or had stopped, the reason(s) was ascertained. In addition, the patients were asked to bring a morning urine sample (without telling them the reason) which was analysed, blind to treatment allocation, for aspirin using a modification of the ferric chloride test. The result was recorded if the patient claimed he or she was taking the trial 
medication. In the "low dose" group (300 mg aspirin in the morning) this test proved unreliable, probably because many patients collected overnight urine before taking the morning tablets. Compliance was therefore tested only in the "high dose" group (it was hardly likely to have been less in the "low dose" group) and contamination with non trial aspirin in the "placebo" group. From 1985-86 most surviving patients had a venous blood sample taken which was mailed to Oxford for further analysis, blind to treatment allocation, including haematocrit and plasma urea levels.

\section{Statistical analysis}

This was by standard log rank tests ${ }^{3}$ of time to first event (or first of one or more of several events) and ignoring subsequent events. This contrasted the number of affected patients allocated to treatment $(O)$ with the number that would have been expected $(E)$ in the absence of any real effect of treatment. The conditional variance $(\mathrm{V})$ of $(\mathrm{O}-\mathrm{E})$ was used both for calculating the standard deviation (S) and for estimating the odds ratios (event rate ratios) and their $95 \%$ confidence intervals. ${ }^{5}$ The three patient groups were otherwise compared with conventional analysis of variance (continuous variables) and chi squared analysis (for discontinuous variables). Interim results were examined every 12 months by the data monitoring committee who were asked to inform the collaborators if one or other, or both combined, aspirin groups deviated more than three standard deviations from the expected on the null hypothesis that treatment had no effect on the events chosen for the fundamental analyses. In the event, recruitment and follow up were continued without stopping the trial early.

\section{Definitions}

A transient ischaemic attack was an acute disturbance of focal neurological or monocular (amaurosis fugax) function with symptoms lasting less than 24 hours and thought to be due to vascular disease of an arterial embolic or thrombotic kind. Neurological signs of no functional significance (for example, reflex asymmetry, extensor plantar response) may have been found subsequently and were recorded at trial entry.

A minor stroke was an acute disturbance of focal neurological function with symptoms lasting more than 24 hours, but less than a week. Neurological signs of no functional significance (see above) were allowed thereafter. If possible, CT scanning was carried out to diagnose intracerebral bleeding, but otherwise the cause of the event was assumed to be infarction due to arterial thromboembolism.

A non fatal major stroke was an acute disturbance of focal neurological function with symptoms lasting more than one week and thought to be due to an intracranial vascular disturbance. The distinction between intracerebral haemorrhage and cerebral infarction was made by CT only if it was done within three weeks of the onset of the stroke. Otherwise the cause of the stroke was classified as "unknown". The severity of the stroke was assessed approximately six months after the onset by a modification of the Rankin scale ${ }^{6}$; strokes scoring from zero to two were counted as "non-disabling" and those scoring from three to five were counted as "disabling":

0 No symptoms at all

1 No significant disability and able to carry out all duties

2 Slight disability. Unable to carry out some previous activities but able to look after own affairs without assistance

3 Moderate disability. Requiring some help but able to walk without assistance

4 Moderately severe disability. Unable to walk without assistance and unable to attend to own bodily needs without assistance

5 Severe disability. Bedridden, incontinent and requiring constant nursing care and attention

Fatal major strokes were defined as previously described except for the distinction between haemorrhage and infarction, which was sometimes possible at necropsy. A stroke was deemed fatal if it led to death within days of onset, or if later death was due to the complications of the stroke (usually pneumonia) which would have been unlikely to have occurred if there had been no prior stroke.

Non-fatal myocardial infarction was diagnosed on the basis of ECG and cardiac enzyme changes along with the appropriate clinical history.

Fatal myocardial infarction was defined as above except in a few cases there was necropsy evidence of definite infarction, or very occasionally definite acute thrombosis of a coronary artery in the presence of an appropriate clinical history.

Sudden death, ischaemic heart disease at necropsy examination. This category was used for patients who died suddenly, or more or less suddenly, and the necropsy examination showed no definite cause of death other than the presence of coronary atheroma.

Sudden death, no necropsy examination, was a category applied to patients who died suddenly, or more or less suddenly, where there was usually very little clinical history, except perhaps a story of chest pain, and no necropsy examination. Many of these patients were known to have had ischaemic heart disease on the basis of a past history of angina or myocardial infarction, but there was no reliable evidence (that is, necropsy examination) that ischaemic heart disease was the only likely cause of death.

Ruptured aortic aneurysm death was used for those patients who had necropsy or operative confirmation.

Other ischaemic heart disease death was a category for patients whose deaths were probably due to ischaemic heart disease although there was no evidence of definite myocardial infarction, and they did not die suddenly. These patients usually died of cardiac failure and were known to have ischaemic heart disease on the basis of the history and possibly necropsy examination. 
Table 1 Protocol deviations

\begin{tabular}{|c|c|c|c|}
\hline & $\begin{array}{l}1200 \mathrm{mg} \text { Aspirin } \\
(n=820)\end{array}$ & $\begin{array}{l}300 \mathrm{mg} \text { Aspirin } \\
(n=810)\end{array}$ & $\begin{array}{l}\text { Placebo } \\
(n=816)\end{array}$ \\
\hline Intracranial tumours & 5 & 4 & 2 \\
\hline $\begin{array}{l}\text { Acoustic neuroma } \\
\text { A }\end{array}$ & 0 & 1 & 0 \\
\hline Meningioma & 3 & 1 & 1 \\
\hline Malignant cerebral tumour & 2 & 2 & 1 \\
\hline Age $<40$ years & 2 & 2 & 4 \\
\hline Plasma urea $>10 \mathrm{mM} / 1$ & $1 \overline{1}$ & 12 & 9 \\
\hline Haematocrit $>55 \%$ & 2 & 0 & 1 \\
\hline Haemoglobin $<10 \mathrm{~g} / \mathrm{dl}$ & 1 & 1 & 0 \\
\hline No cerebrovascular event in 3 months & & & \\
\hline pre-randomisation & 15 & 15 & 21 \\
\hline $\begin{array}{l}\text { Taking aspirin for } 90 \text { or more days before } \\
\text { randomisation }\end{array}$ & 13 & 4 & 10 \\
\hline Myocardial infarction $<3$ months & & & \\
\hline pre-randomisation & 1 & 3 & 3 \\
\hline Past subarachnoid haemorrhage & 1 & 0 & 1 \\
\hline
\end{tabular}

Table 2 Number (and \%) of patients with various categories of cerebrovascular events

\begin{tabular}{|c|c|c|c|c|c|c|}
\hline \multirow[b]{2}{*}{$\begin{array}{l}\text { Any transient cerebral ischaemic attack } \\
\text { Only transient cerebral ischaemic attack } \\
\text { Any amaurosis fugax } \\
\text { Only amaurosis fugax } \\
\text { Any minor stroke } \\
\text { Only minor stroke } \\
\text { ^Infarction on CT scan } \\
\dagger_{\text {“Significant” arterial disease }}\end{array}$} & \multicolumn{2}{|c|}{$\begin{array}{l}1200 \mathrm{mg} \text { Aspirin } \\
(n=815)\end{array}$} & \multicolumn{2}{|c|}{$\begin{array}{l}300 m g \text { Aspirin } \\
(n=806)\end{array}$} & \multicolumn{2}{|c|}{$\begin{array}{l}\text { Placebo } \\
(n=814)\end{array}$} \\
\hline & $\begin{array}{r}572 \\
469 \\
163 \\
112 \\
178 \\
118 \\
84 \\
134\end{array}$ & $\begin{array}{l}(70) \\
(58) \\
(20) \\
(14) \\
(22) \\
(14) \\
(21) \\
(56)\end{array}$ & $\begin{array}{r}561 \\
464 \\
170 \\
111 \\
171 \\
116 \\
72 \\
130\end{array}$ & $\begin{array}{l}(70) \\
(58) \\
(21) \\
(14) \\
(21) \\
(14) \\
(19) \\
(57)\end{array}$ & $\begin{array}{r}586 \\
488 \\
142 \\
83 \\
186 \\
123 \\
82 \\
116\end{array}$ & $\begin{array}{l}(72) \\
(60) \\
(17) \\
(10) \\
(23) \\
(15) \\
(21) \\
(52)\end{array}$ \\
\hline
\end{tabular}

$\star 1187(49 \%)$ patients had a pre-randomisation CT scan.

+689 $(28 \%)$ patients had cerebral angiography; "significant" disease includes internal carotid artery origin stenosis or occlusion, intracranial carotid disease, etc.

Gastrointestinal haemorrhage deaths were those that were clearly a result of gastrointestinal bleeding.

Other vascular deaths were patients thought to have died as a result of a vascular event but who could not be placed in any of the other categories. This category included one patient with pulmonary embolism with no underlying cause, two with cardiac valvular disease, and patients in whom there was no information other than a death certificate diagnosis of stroke, myocardial infarction or some other vascular event.

Non vascular deaths included those patients who definitely died of some disorder unrelated to vascular disease, often cancer.

Unknown was a small category where we had no useful information at all on the cause of death.
Coronary events included fatal and non-fatal myocardial infarction, sudden death with or without necropsy examination, and other ischaemic heart disease death.

Vascular deaths included all deaths which were not definitely non vascular, that is, fatal stroke, fatal myocardial infarction, sudden death, ruptured aortic aneurysm, other ischaemic heart disease death, other vascular death, fatal gastrointestinal haemorrhage-and unknown cause of death. It was important that the last two categories were included in the fundamental analyses so that they covered deaths due to the complication of treatment, and deaths which might have been vascular and therefore amenable to treatment; this strategy provides a conservative estimate of any benefit of aspirin.

\section{Results}

Of the 2449 patients that were randomised, 11 were soon found to have intracranial tumours thought to have caused their focal neurological symptoms (table 1). "Blind to treatment" allocation, they were withdrawn from formal follow up and analysis. However, at the end of the trial six were known to be still alive and five had died from their tumours: two in the "high dose" group, two in the "low dose" group, and one in the "placebo" group. None of these patients with tumours was known to have had a stroke or myocardial infarction. Three randomisations were void since they were given in error to the wrong patients. Therefore, 2435 patient results were available for analysis and none was lost to follow up, which continued from one to seven years (mean about four); there were 3428 patient years of follow up in the "high dose" group, 3516 in "low dose" group, and 3581 in the "placebo" group (total 10525 ). There were some minor protocol deviations (table 1), but these were not considered sufficient to withdraw the patient from follow up or from the analysis. During the trial follow up it became clear that 13 patients almost certainly had never had TIAs or minor strokes but they were still kept on follow up and included in the analysis (migraine, giant cell arteritis, transient global amnesia, partial seizures, micturition syncope).

Table 3 Prevalence of vascular risk factors

\begin{tabular}{|c|c|c|c|}
\hline & $\begin{array}{l}1200 \mathrm{mg} \text { Aspirin } \\
(n=815)\end{array}$ & $\begin{array}{l}300 m g \text { Aspirin } \\
(n=806)\end{array}$ & $\begin{array}{l}\text { Placebo } \\
(n=814)\end{array}$ \\
\hline Male & $601(74)$ & $603(75)$ & $575(71)$ \\
\hline Regular smokers & $444(54)$ & $431(53)$ & $417(51)$ \\
\hline Treated hypertension & $214(26)$ & $225(28)$ & $221(27)$ \\
\hline Treated hypertension and/or diastolic $B P \geqslant 100 \mathrm{~mm} \mathrm{Hg}$ & $305(37)$ & $318(39)$ & $332(41)$ \\
\hline Past myocardial infarction & $78(10)$ & $77(10)$ & $87(11)$ \\
\hline Angina & $103(13)$ & $129(16)$ & $125(15)$ \\
\hline Past myocardial infarction and/or angina & $146(18)$ & $164(20)$ & $165(20)$ \\
\hline Cardiomegaly on chest radiograph & $62(8)$ & $68(8)$ & $75(9)$ \\
\hline Cardiac failure & $11(1)$ & $12(1)$ & $8(1)$ \\
\hline Atrial fibrillation & $21(3)$ & $13(2)$ & $15(2)$ \\
\hline Cardiac valvular disease & $14(2)$ & $15(2)$ & $27(3)$ \\
\hline Treated hyperlipidaemia & $17(2)$ & $24(3)$ & $14(2)$ \\
\hline \multicolumn{4}{|l|}{ Treated hyperlipidaemia and/or } \\
\hline plasma cholesterol $\geqslant 7.0 \mathrm{mM} / 1$ & $264(32)$ & $306(38)$ & $286(35)$ \\
\hline Treated diabetes & $30(4)$ & $29(4)$ & $31(4)$ \\
\hline \multicolumn{4}{|l|}{ Treated diabetes } \\
\hline $\begin{array}{c}\text { and/or plasma glucose } \geqslant 10 \mathrm{mM} / 1 \\
\text { Peripheral vascular disease }\end{array}$ & $\begin{array}{c}35(4) \\
109(13)\end{array}$ & $36(4)$ & $35(4)$ \\
\hline $\begin{array}{l}\text { Peripheral vascular disease } \\
\text { Retinal emboli }\end{array}$ & $\begin{array}{c}109(13) \\
22(3)\end{array}$ & $\begin{array}{c}104(13) \\
24(3)\end{array}$ & $\begin{array}{l}85(10) \\
23(3)\end{array}$ \\
\hline Previous non-disabling major stroke & $27(3)$ & $26(3)$ & $28(3)$ \\
\hline
\end{tabular}

()$=\%$ 
Table 4 Vascular risk factors, continuous variables: mean (SD)

\begin{tabular}{|c|c|c|c|}
\hline & $\begin{array}{l}1200 m g \text { Aspirin } \\
(n=815)\end{array}$ & $\begin{array}{l}300 m g \text { Aspirin } \\
(n=806)\end{array}$ & $\begin{array}{l}\text { Placebo } \\
(n=814)\end{array}$ \\
\hline $\begin{array}{l}\text { Age (years) } \\
\text { Systolic BP (mm Hg) } \\
\text { Diastolic BP }(\mathrm{mm} \mathrm{Hg}) \\
\text { Random plasma cholesterol }(\mathrm{mM} / \mathrm{l}) \\
\text { Haematocrit }(\%) \\
\text { Random plasma glucose }(\mathrm{mM} / \mathrm{l}) \\
\text { Obesity index }\left(\mathrm{kg} / \mathrm{m}^{2}\right) \\
\text { Heart rate } / \text { minute }\end{array}$ & $\begin{array}{l}59 \cdot 9(9 \cdot 16) \\
151(24) \\
88(11) \\
6 \cdot 0(1 \cdot 38) \\
44(3 \cdot 9) \\
5 \cdot 2(1 \cdot 45) \\
25 \cdot 3(3 \cdot 39) \\
69(14 \cdot 3)\end{array}$ & $\begin{array}{l}60 \cdot 0(8 \cdot 92) \\
150(25) \\
88(12) \\
6 \cdot 1(1 \cdot 43) \\
44(3 \cdot 8) \\
5 \cdot 3(1 \cdot 51) \\
25 \cdot 5(3 \cdot 82) \\
68(13 \cdot 6)\end{array}$ & $\begin{array}{l}59 \cdot 5(9 \cdot 04) \\
151(26) \\
88(12) \\
6 \cdot 0(1 \cdot 39) \\
44(3 \cdot 9) \\
5 \cdot 3(1 \cdot 55) \\
25 \cdot 1(3 \cdot 43) \\
69(14 \cdot 1)\end{array}$ \\
\hline
\end{tabular}

Table 5 Number (and \%) of patients having various treatments at randomisation

\begin{tabular}{lccc}
\hline & $\begin{array}{c}1200 \mathrm{mg} \text { Aspirin } \\
(n=815)\end{array}$ & $\begin{array}{l}300 \mathrm{mg} \text { Aspirin } \\
(n=806)\end{array}$ & $\begin{array}{l}\text { Placebo } \\
(n=814)\end{array}$ \\
\hline Beta-blockers & $136(17)$ & $160(20)$ & $145(18)$ \\
Diuretics & $152(19)$ & $156(19)$ & $145(18)$ \\
Other drugs for hypertension & $65(8)$ & $60(7)$ & $61(7)$ \\
Aspirin & $126(15)$ & $115(14)$ & $120(15)$ \\
Dipyridamole & $51(6)$ & $46(6)$ & $35(4)$ \\
Anticoagulants & $5(1)$ & $6(1)$ & $3(0)$ \\
Lipid lowing drugs & $4(0)$ & $3(0)$ & $3(0)$ \\
Previous carotid endarterectomy & $22(3)$ & $15(2)$ & $12(1)$ \\
\hline
\end{tabular}

Baseline characteristics

The three groups were well matched (tables 25), particularly for all the known and important prognostic variables for stroke and myocardial infarction recorded at trial entry. There were slightly more hyperlipidaemic patients in the "low dose" than in the "high dose" aspirin group ( $38 \%$ versus $32 \%, \mathrm{p}<0.05)$ but the mean plasma cholesterol levels were almost identical ( 6.1 versus $6.0 \mathrm{mM} /$ litre); cardiac valvular disease was slightly less common in the aspirin groups taken together than in the placebo group $(1.8 \%$ versus $3.3 \% \mathrm{p}<0.05)$ but the absolute percentage difference was very small and mostly accounted for by aortic sclerosis and mitral leaflet prolapse which are both of dubious embolic significance; only amaurosis fugax was somewhat less common in the placebo group than in the combined aspirin groups $(10 \%$ versus $14 \%, p<0.05)$, a difference that became insignificant when any amaurosis fugax was considered. These, and

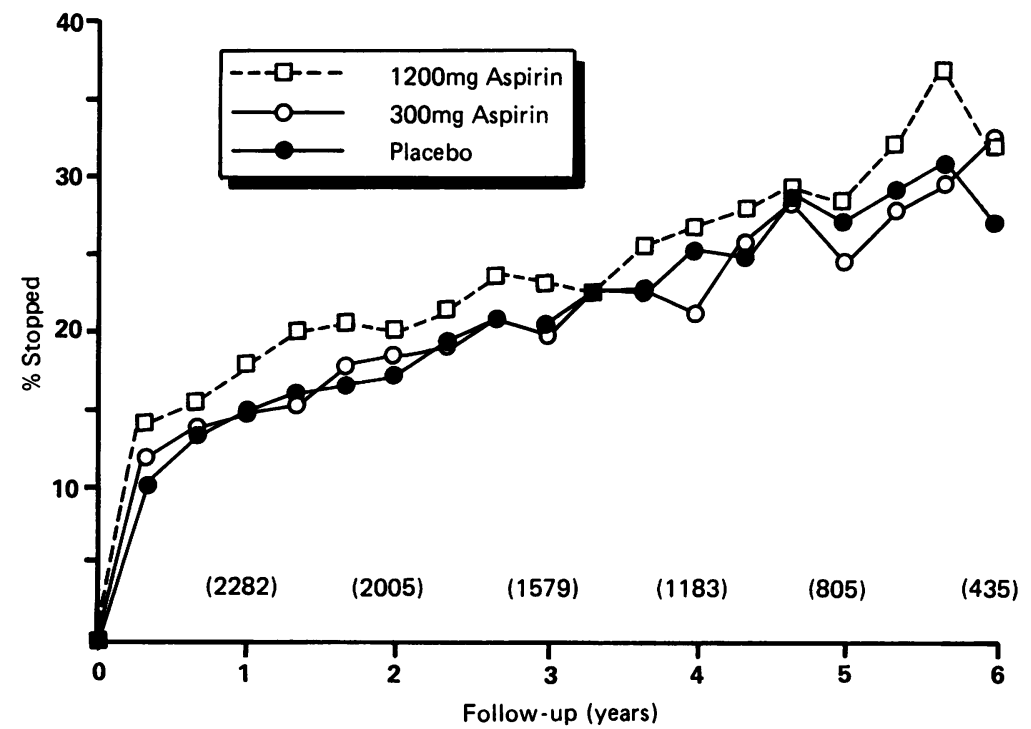

Figure 1 Stated compliance with trial medication during the follow up period. The percentage of patients who said that they had definitely stopped trial medication at each four month follow up is indicated on the $y$-axis. The numbers in brackets along the $x$-axis refer to the number of patients surviving, and followed up, at each one year period. other small differences, favoured one or other of the three groups but had no material effect on the main analyses.

The patients were largely male $(73 \%)$, aged about 60 years and had mostly experienced transient cerebral ischaemic attacks or amaurosis fugax. They had a high prevalence of vascular risk factors, some had infarction visible on CT scan (20\%), which may or may not have been relevant to their neurological symptoms, and about half of those having a cerebral angiogram showed arterial, presumed atheromatous, disease of haemodynamic or embolic significance. They were therefore, very representative of the type of patient with acute, but mild cerebrovascular disease who present to medical attention and are referred to hospital based neurologists in the UK.

\section{Deviation from allocated treatment}

By the first four months follow up about $12 \%$ of the patients had definitely stopped trial medication, although a few eventually restarted on regular or enteric coated trial tablets at some later stage (fig 1). Since the reasons for withdrawal of trial medication mostly concerned aspirin-related adverse effects (table 6) it was not surprising that throughout the trial the proportion stopped was consistently greatest in the "high-dose" group, eventually reaching about $30 \%$ by six years. The difference between the "low dose" group and the "placebo" group was less marked. The frequency of other reasons for stopping trial medication was quite similar between the three treatment groups.

Overall, the urine test used for compliance was reassuring (at least in the urines presented for analysis which might have been more often in those actually taking trial medication than in those not doing so); in the "high dose" group, of the 3391 urines received and analysed 2541 $(75 \%)$ were definitely positive for aspirin, and in the "placebo" group only 44 of the 3610 urines $(1 \cdot 2 \%)$ were positive.

\section{Adverse effects}

The number and proportion of patients who 
Table 6 Reasons for stopping trial medication; number of patients

\begin{tabular}{|c|c|c|c|}
\hline & $\begin{array}{l}1200 m g \text { Aspirin } \\
(n=815)\end{array}$ & $\begin{array}{l}300 \text { mg Aspirin } \\
(n=806)\end{array}$ & $\begin{array}{l}\text { Placebo } \\
(n=814)\end{array}$ \\
\hline $\begin{array}{l}\text { Adverse effects } \\
\text { Patient refused to continue } \\
\text { Given a contaminating drug } \\
\text { Given non trial aspirin } \\
\text { Intercurrent illness } \\
\text { Other physician insisted } \\
\text { General practitioner insisted } \\
\text { Excessive TIAs or amaurosis fugax } \\
\text { Patient moved away }\end{array}$ & $\begin{array}{r}160 \\
35 \\
9 \\
10 \\
14 \\
16 \\
5 \\
4 \\
1\end{array}$ & $\begin{array}{r}106 \\
53 \\
10 \\
15 \\
6 \\
13 \\
6 \\
2 \\
1\end{array}$ & $\begin{array}{r}97 \\
58 \\
26 \\
16 \\
10 \\
16 \\
7 \\
3 \\
3\end{array}$ \\
\hline
\end{tabular}

^For example, anticoagulants.

Table 7 Adverse effects reported during follow-up; number (and \%) of patients

\begin{tabular}{lccc}
\hline & $\begin{array}{l}1200 \text { mg Aspirin } \\
(\boldsymbol{n}=815)\end{array}$ & $\begin{array}{l}300 \text { mg Aspirin } \\
(\boldsymbol{n}=806)\end{array}$ & $\begin{array}{c}\text { Placebo } \\
(\boldsymbol{n}=814)\end{array}$ \\
\hline $\begin{array}{l}\text { Upper gastrointestinal symptoms } \\
\text { (nausea, abdominal pain, vomiting, heartburn) }\end{array}$ & $338(41)$ & $253(31)$ & $209(26)$ \\
Constipation & $56(7)$ & $48(6)$ & $20(2)$ \\
Abdominal flatulence & $4(0)$ & $6(1)$ & $8(1)$ \\
Diarrhoea/“colitis" & $8(1)$ & $16(2)$ & $5(1)$ \\
Gastrointestinal haemorrhage & $39(5)$ & $25(3)$ & $9(1)$ \\
Bruising & $13(2)$ & $12(1)$ & $3(0)$ \\
Nose bleed & $9(1)$ & $9(1)$ & $7(1)$ \\
Retinal haemorrhage & $0(0)$ & $1(0)$ & $1(0)$ \\
Other abnormal bleeding & $16(2)$ & $13(2)$ & $8(1)$ \\
Gout & $23(3)$ & $25(3)$ & $21(3)$ \\
Tiredness & $24(3)$ & $17(2)$ & $19(2)$ \\
Skin rash & $17(2)$ & $13(2)$ & $17(2)$ \\
Dizziness/tinnitus & $6(1)$ & $11(1)$ & $7(2)$ \\
Depression, irritability & $2(0)$ & $3(0)$ & $2(0)$ \\
Wheezy chest & $0(0)$ & $2(0)$ \\
\hline
\end{tabular}

Footnote for each type of adverse effect patients were only counted once. If a patient had more than one type of adverse effect he/she was counted more than once.

reported various adverse effects are shown by allocated treatment group in table 7 . There was a clear cut and statistically significant dose response effect for upper gastrointestinal symptoms although these were common in the "placebo" group; the odds ratio for the "low dose" group compared with the "placebo" group was 1.32 (95\% confidence interval $(\mathrm{CI})$ $1.06-1.65)$ and the odds ratio for the "high dose" group compared with the "low dose" group was 1.54 (95\% CI 1.25-1.89, fig 2). There was no definite dose response relationship for constipation (fig 2) but, taken together, the odds ratio for both aspirin groups com-

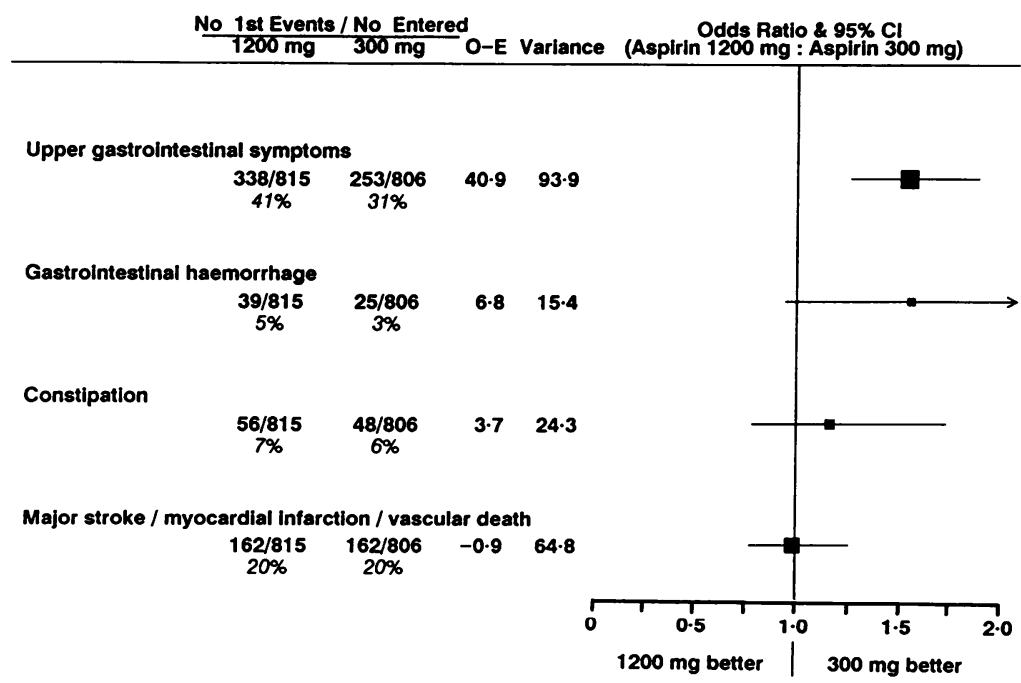

Figure 2 Comparison of $1200 \mathrm{mg}$ versus $300 \mathrm{mg}$ daily aspirin: main adverse effects and main vascular events; "intention-to-treat" analysis of proportion of patients experiencing at least one event. In the log rank analysis of time to "major stroke, myocardial infarction, vascular death", this small difference is reversed yielding an odds ratio of 1.03, see table 13. The filled boxes are proportional to the amount of information (that is, number of events) contained in the analysis. pared with "placebo" was $2 \cdot 72(95 \%$ CI $1 \cdot 68$ 4.40). Surprisingly, both aspirin groups taken together were less likely to complain of dizziness and tinnitus $(p<0.05)$ than the "placebo" group but, as expected, the aspirin groups were more likely to complain of bruising (odds ratio $4.23,95 \%$ CI $1 \cdot 28-14 \cdot 0$ ) although there was no obvious dose response relationship. Diarrhoea and "colitis" were more frequent in the aspirin groups but the numbers were small and the differences not statistically significant. There were no significant or substantial differences in other reported adverse effects (such as gout) except for the most important, gastrointestinal haemorrhage (table 8).

In the "placebo" group there were about three gastrointestinal haemorrhages per thousand patient years of follow up, in the "low dose" group about seven, and in the "high dose" group about 11; this was a clearcut dose response effect. The odds ratio for gastrointestinal haemorrhage comparing the "high-dose" with the "low dose" aspirin groups was 1.62 (95\% CI 0.94-2.79, fig 2) and comparing the "low dose" with the "placebo" group was 2.57 (95\% CI 1 20-5.53). Less than half the patients with gastrointestinal haemorrhage required hospital admission (table 8) and only two died (one patient was not on trial medication at the time). Although it was quite clear that aspirin increased the incidence of gastrointestinal symptoms, these were mostly mild, resolved when medication was withdrawn, and if serious (such as, if bleeding occurred) led to almost no mortality nor permanent morbidity. Presumably if we had used soluble, dispersible or enteric coated trial medication for all patients the problem might have been reduced. 
Table 8 Gastrointestinal haemorrhages during trial follow up (all events until 30 September 1986 inclusive)

\begin{tabular}{|c|c|c|c|}
\hline \multirow[b]{2}{*}{ Severity } & \multicolumn{3}{|l|}{ Number of patients } \\
\hline & $\begin{array}{l}1200 \mathrm{mg} \text { Aspirin } \\
(n=815)\end{array}$ & $\begin{array}{l}300 m g \text { Aspirin } \\
(n=806)\end{array}$ & $\begin{array}{l}\text { Placebo } \\
(n=814)\end{array}$ \\
\hline $\begin{array}{l}\text { Uncertain/trivial } \\
\text { Not admitted to hospital } \\
\text { Admitted to hospital } \\
\text { Admitted and transfused } \\
\text { Admitted and operated } \\
\text { Fatal }\end{array}$ & $\begin{array}{l}10(3)^{\star} \\
10 \\
11 \\
2 \\
4 \\
2(1)\end{array}$ & $\begin{array}{l}9(3) \\
6(2) \\
2 \\
6 \\
2 \\
0\end{array}$ & $\begin{array}{l}5(3) \\
2(1) \\
1(1) \\
0 \\
1(1) \dagger \\
0\end{array}$ \\
\hline Total & $39(4)$ & $25(5)$ & $9(6)$ \\
\hline
\end{tabular}

*Numbers in brackets are the number of patients not on trial medication at the time of the bleed; they are, however, included in the non-bracketed numbers (that is, 73 patients had a bleed although 15 of them were not on trial medication at the time). No

patient had more than one bleeding episode.
$\dagger$ This contributed to the death of the patient, but was not the underlying cause which was cerebral infarction due to carotid endarterectomy.

Table 9 Changes in mean (SD) blood urea and haematocrit during follow up

\begin{tabular}{|c|c|c|c|}
\hline & $1200 \mathrm{mg}$ Aspirin & 300 mg Aspirin & Placebo \\
\hline $\begin{array}{l}\text { Mean plasma urea }(\mathrm{mmol} / \mathrm{l}) \\
\text { At randomisation } \\
\text { In } 1985 / 86 \\
\text { Mean difference } \\
\text { 2P }\end{array}$ & $\begin{aligned} & \mathbf{n}=632 \\
& 5 \cdot 64(1 \cdot 72) \\
& 7 \cdot 65(3 \cdot 19) \\
& 2 \cdot 01(0.12) \\
< & 0.001\end{aligned}$ & $\begin{array}{l}\mathrm{n}=605 \\
5.61(1.57) \\
7.53(4.01) \\
1.92(0.16) \\
<0.001\end{array}$ & $\begin{array}{l}\mathbf{n}=599 \\
5.50(1.58) \\
7.46(4.01) \\
1.95(0.17) \\
<0.0001\end{array}$ \\
\hline $\begin{array}{l}\text { Mean haematocrit }(\%) \\
\text { At randomisation } \\
\text { In } 1985 / 86 \\
\text { Meandifference } \\
\text { 2P }\end{array}$ & $\begin{array}{l}\mathrm{n}=614 \\
44 \cdot 2(3.90) \\
43 \cdot 7(5 \cdot 44) \\
-0.56(0 \cdot 22) \\
<0.02\end{array}$ & $\begin{array}{l}\mathrm{n}=602 \\
44 \cdot 1(3 \cdot 78) \\
43 \cdot 2(4 \cdot 92) \\
-0.91(0 \cdot 20) \\
<0.001\end{array}$ & $\begin{array}{l}\mathrm{n}=594 \\
43.9(3.92) \\
43.0(5.11) \\
-0.91(0.21) \\
<0.001\end{array}$ \\
\hline
\end{tabular}

Note the comparisons were made only for patients alive in $1985 / 86$ and for whom a blood sample was available (in about $10 \%$ a blood sample was forgotten, broke in the post, or was unsuitable for analysis).

During the follow up there was a highly statistically significant increase in the mean blood urea which was very similar in all three treatment groups (table 9); this increase was less in the "low dose" aspirin than in the "placebo" group. Presumably, this change was a reflection of increasing age. There was also a statistically significant but very small decrease in the mean haematocrit in all three groups. This decrease was lowest in the "high-dose" group and equal in the "placebo" and "lowdose" groups (table 9).

Co-interventions and vascular risk factors during follow up

A small proportion of patients had a carotid endarterectomy or other vascular surgical procedure during follow up (table 10). A small proportion also received various antithrombotic treatments, particularly non trial aspirin, but there were no large or statistically significant differences between the three groups.

Reported smoking behaviour was probably not particularly accurate, but would not have been biased by any knowledge of the nature of the trial medication. Smoking reported at any follow up, and on $75 \%$ or more of the follow ups, was very similar in the three groups and there were no statistically significant differences (table 10).
Blood pressure during follow up was similar in all three groups although there was a tendency for the aspirin groups to run slightly higher systolic pressures than the "placebo" group (fig 3). The general fall in pressure may have been due to a combination of regression to the mean, treatment as a consequence of repeated surveillance and therefore a high chance of detecting hypertension, and also to repeating the measurement in familiar surroundings.

\section{Major events}

All major vascular events of interest and all non-vascular deaths in the patients during follow up, irrespective of compliance with trial medication, are shown in tables 11 and 12 for males, females and both sexes combined, and for "high-dose" aspirin, "low-dose" aspirin and "placebo". These events were often not mutually exclusive; many patients had more than one (for example, minor stroke followed by non-fatal myocardial infarction followed by non-vascular death).

\section{"High-dose" versus "low-dose" aspirin}

For all categories and combinations of event (with one exception) there were no statistically significant differences between the two dose

Table 10 Co-interventions and vascular risk factors during follow up; number (and \%) of patients

\begin{tabular}{lccc}
\hline & $\begin{array}{l}1200 \text { mg Aspirin } \\
(n=815)\end{array}$ & $\begin{array}{l}600 \text { mg Aspirin } \\
(n=806)\end{array}$ & $\begin{array}{c}\text { Placebo } \\
(n=814)\end{array}$ \\
\hline Carotid endarterectomy & $44(5)$ & $36(4)$ & $37(4)$ \\
Extra to intracranial bypass & $4(0)$ & $2(0)$ & $5(0)$ \\
Coronary artery surgery & $10(1)$ & $5(0)$ & $7(1)$ \\
Anticoagulants & $41(5)$ & $34(4)$ & $52(6)$ \\
Non trial aspirin & $80(10)$ & $77(10)$ & $95(12)$ \\
Dipyridamole & $44(5)$ & $36(4)$ & $45(6)$ \\
Venesection & $16(2)$ & $33(4)$ & $22(3)$ \\
Smoking at any time & $400(49)$ & $419(52)$ & $395(48)$ \\
Smoking at 75\% or more follow ups & $168(21)$ & $134(17)$ & $142(17)$ \\
\hline
\end{tabular}



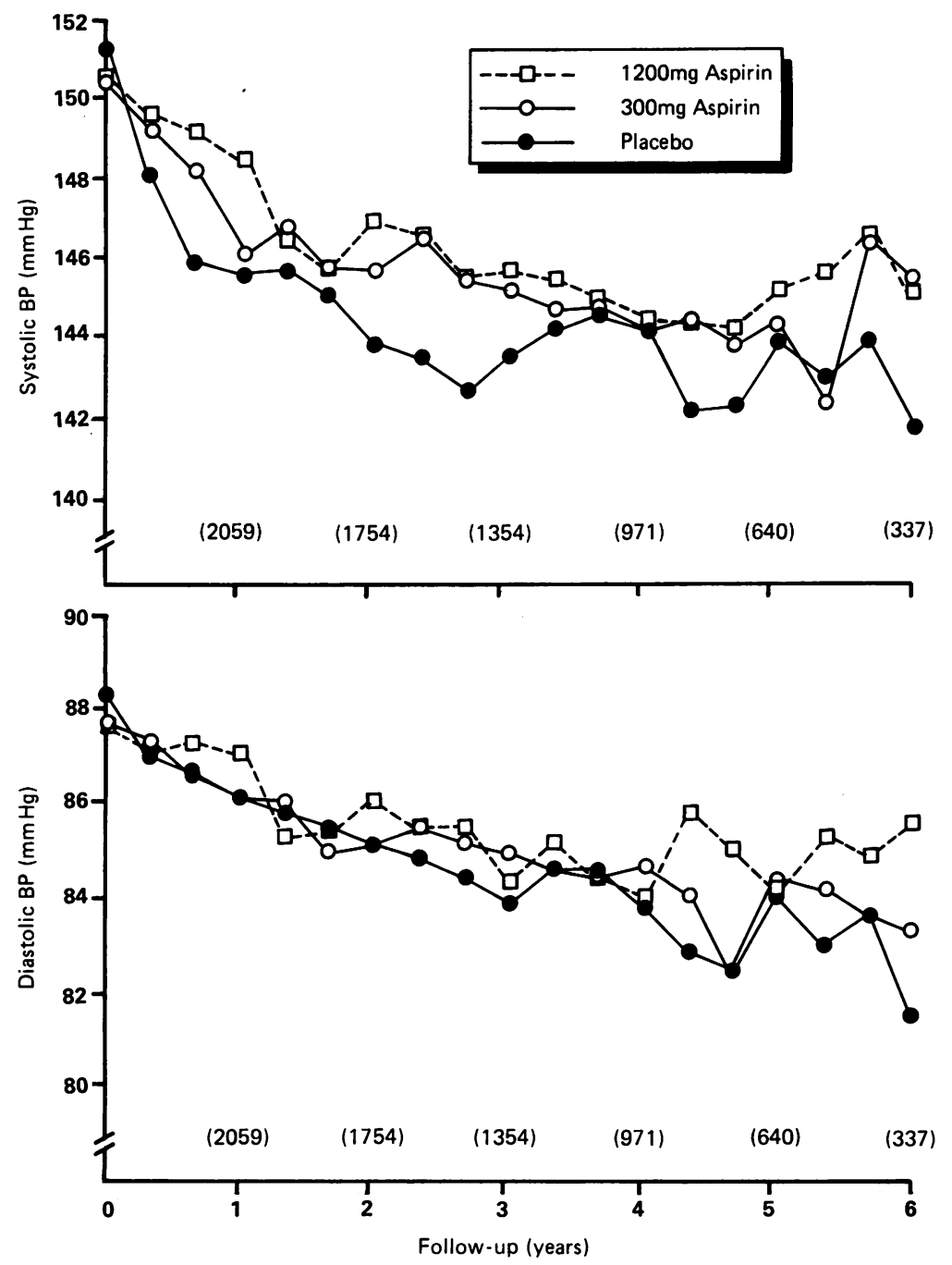

Figure 3 Systolic and diastolic blood pressure during follow up. The numbers in brackets refer to the number of surviving patients with a blood pressure recorded at each one year follow up point.

regimes in males, females and both sexes combined. The single exception of non vascular death in females was based on only four deaths with a correspondingly wide confidence interval (table 13 and fig 2). Although all the confidence intervals were fairly wide almost all the odds ratios were close to unity and we therefore thought that there was unlikely to be any important difference between the efficacy of the two doses. Furthermore, equal efficacy is biologically plausible ${ }^{7}$ and supported by the overview of all similar trials. ${ }^{2}$ Both aspirin dose groups were therefore combined in subsequent analyses.

\section{Aspirin ("high-dose" combined with}

"low-dose") versus placebo: women

As only about a quarter of the patients were female, the number of events was small and the confidence interval of the odds ratios correspondingly wide (table 14). Although there was a statistically significant reduction in nonvascular deaths in the combined aspirin group this was based on only 13 deaths and likely to have been an extreme effect of chance (see below).

\section{Aspirin ("high-dose" and "low-dose") versus} placebo: men

For men there seemed to be a much clearer (and statistically significant) benefit in those who were allocated aspirin (table 14). Statistical significance was achieved on one of the main outcomes of interest; "major stroke, myocardial infarction or vascular death", odds reduction $20 \%$, with $95 \%$ confidence interval of $1-$ $35 \%$. This reduction was more extreme if non vascular death was also included, but as the beneficial effect of aspirin on non-vascular death was probably due to the play of chance (see below) we would not want to overemphasise this particular analysis. Other categories of event showed similar trends but were not statistically significant, presumably because the numbers were smaller than in the main overall analysis.

\section{Aspirin ("high-dose" and "low-dose") versus} placebo: all patients (fig 4)

This is our preferred analysis because on the basis of the above results (table 14) and the overview of all similar trials we were not convinced that the response to aspirin was definitely different in males and females. The

Table 11 Number (and \%) of patients with an event between 25 July 1979 and 30 September 1986 inclusive by allocated treatment group. For each category only one event is counted per patient (for example, of 575 males allocated placebo there were 147 who had a major stroke or a myocardial infarction or who died a vascular death)

\begin{tabular}{|c|c|c|c|c|c|c|c|c|c|}
\hline \multirow[b]{2}{*}{ Events } & \multicolumn{3}{|c|}{$1200 \mathrm{mg}$ Aspirin } & \multicolumn{3}{|c|}{$300 \mathrm{mg}$ Aspirin } & \multicolumn{3}{|l|}{ Placebo } \\
\hline & $\begin{array}{l}M \\
(601)\end{array}$ & $\begin{array}{l}F \\
(214)\end{array}$ & $\underset{(815)}{M+F}$ & $\begin{array}{l}M \\
(603)\end{array}$ & $\begin{array}{l}F \\
(203)\end{array}$ & $\underset{(806)}{M+F}$ & $\begin{array}{l}M \\
(575)\end{array}$ & $\begin{array}{l}F \\
(239)\end{array}$ & $\underset{(814)}{M+F}$ \\
\hline $\begin{array}{l}\text { Stroke } \\
\text { Fatal } \\
\text { Disabling major and/or fatal } \\
\text { Major and/or fatal } \\
\text { of which: }{ }^{\star} \text { definite haemorrhage } \\
\text { definite infarct } \\
\text { All (minor/major/fatal) }\end{array}$ & $\begin{array}{l}12(2 \cdot 0) \\
31(5 \cdot 2) \\
63(10 \cdot 5) \\
4(0 \cdot 7) \\
25(4 \cdot 2) \\
75(12 \cdot 5)\end{array}$ & $\begin{array}{l}8(3 \cdot 7) \\
16(7 \cdot 5) \\
22(10 \cdot 3) \\
3(1 \cdot 4) \\
6(2 \cdot 8) \\
26(12 \cdot 1)\end{array}$ & $\begin{array}{l}20(2 \cdot 5) \\
47(5 \cdot 8) \\
85(10 \cdot 4) \\
7(0 \cdot 9) \\
31(3 \cdot 8) \\
101(12 \cdot 4)\end{array}$ & $\begin{array}{l}13(2 \cdot 2) \\
31(5 \cdot 1) \\
62(10 \cdot 3) \\
5(0 \cdot 8) \\
14(2 \cdot 3) \\
75(12 \cdot 4)\end{array}$ & $\begin{array}{r}5(2 \cdot 5) \\
13(6 \cdot 4) \\
20(9 \cdot 9) \\
2(1 \cdot 0) \\
9(4 \cdot 4) \\
25(12 \cdot 3)\end{array}$ & $\begin{array}{l}18(2 \cdot 2) \\
44(5 \cdot 5) \\
82(10 \cdot 2) \\
7(0 \cdot 9) \\
23(2 \cdot 9) \\
100(12 \cdot 4)\end{array}$ & $\begin{array}{l}14(2 \cdot 4) \\
37(6 \cdot 4) \\
67(11 \cdot 7) \\
2(0 \cdot 3) \\
26(4 \cdot 5) \\
83(14 \cdot 4)\end{array}$ & $\begin{array}{c}3(1 \cdot 3) \\
9(3 \cdot 8) \\
28(11 \cdot 7) \\
0 \\
9(3 \cdot 8) \\
36(15 \cdot 1)\end{array}$ & $\begin{array}{c}17(2 \cdot 1) \\
46(5 \cdot 7) \\
95(11 \cdot 7) \\
2(0 \cdot 2) \\
35(4 \cdot 3) \\
119(14 \cdot 6)\end{array}$ \\
\hline $\begin{array}{l}\text { Ischaemic heart disease (IHD) } \\
\text { Fatal (sudden, MI, other IHD death) } \\
\text { Coronary Event (non-fatal MI/fatal IHD) }\end{array}$ & $\begin{array}{l}47(7 \cdot 8) \\
61(10 \cdot 1)\end{array}$ & $\begin{array}{r}8(3 \cdot 7) \\
13(6 \cdot 1)\end{array}$ & $\begin{array}{l}55(6 \cdot 7) \\
74(9 \cdot 1)\end{array}$ & $\begin{array}{l}45(7 \cdot 5) \\
69(11 \cdot 4)\end{array}$ & $\begin{array}{r}9(4.4) \\
12(5.9)\end{array}$ & $\begin{array}{l}54(6 \cdot 7) \\
81(10 \cdot 0)\end{array}$ & $\begin{array}{l}43(7 \cdot 5) \\
74(12 \cdot 9)\end{array}$ & $\begin{array}{l}11(4 \cdot 6) \\
16(6 \cdot 7)\end{array}$ & $\begin{array}{l}54(6 \cdot 6) \\
90(11 \cdot 1)\end{array}$ \\
\hline $\begin{array}{l}\text { Combinations } \\
\text { Disabling major stroke/vascular death } \dagger \\
\text { Major stroke/MI/death } \\
\text { All stroke/MI/vascular death } \dagger \\
\text { Major stroke/MI/vascular death } \dagger \\
\end{array}$ & $\begin{array}{r}80(13 \cdot 3) \\
137(12 \cdot 8) \\
134(22 \cdot 3) \\
123(20 \cdot 5) \\
\end{array}$ & $\begin{array}{l}29(13 \cdot 6) \\
41(19 \cdot 2) \\
42(19 \cdot 6) \\
39(18 \cdot 2) \\
\end{array}$ & $\begin{array}{l}109(13.4) \\
178(21 \cdot 8) \\
176(21 \cdot 6) \\
162(19.9) \\
\end{array}$ & $\begin{array}{l}83(13.8) \\
144(23.9) \\
141(23.4) \\
130(21 \cdot 6) \\
\end{array}$ & $\begin{array}{l}23(11 \cdot 3) \\
32(15 \cdot 8) \\
37(18 \cdot 2) \\
32(15 \cdot 8) \\
\end{array}$ & $\begin{array}{l}106(13 \cdot 2) \\
176(21 \cdot 8) \\
178(22 \cdot 1) \\
162(20 \cdot 1) \\
\end{array}$ & $\begin{array}{r}92(16 \cdot 0) \\
166(28 \cdot 9) \\
158(27 \cdot 5) \\
147(25 \cdot 6) \\
\end{array}$ & $\begin{array}{l}19(7 \cdot 9) \\
45(18 \cdot 8) \\
46(19 \cdot 2) \\
39(16 \cdot 3)\end{array}$ & $\begin{array}{l}111(13 \cdot 6) \\
211(25 \cdot 9) \\
204(25 \cdot 1) \\
186(22 \cdot 9)\end{array}$ \\
\hline
\end{tabular}

^For many, the cause of stroke was unknown.

†Includes deaths from gastrointestinal haemorrhage and unknown causes.

MI = Myocardial infarction

$\mathrm{IHD}=$ Ischaemic heart disease. 
Table 12 Death (and \%) by cause and allocated treatment group between 25 July 1979 and 30 September 1986 inclusive

\begin{tabular}{|c|c|c|c|c|c|c|c|c|c|}
\hline \multirow[b]{2}{*}{ Cause of death } & \multicolumn{3}{|c|}{$1200 \mathrm{mg}$ Aspirin } & \multicolumn{3}{|c|}{$300 \mathrm{mg}$ Aspirin } & \multicolumn{3}{|l|}{ Placebo } \\
\hline & $\begin{array}{l}M \\
(601)\end{array}$ & $\begin{array}{l}F \\
(214)\end{array}$ & $\begin{array}{l}M+F \\
(815)\end{array}$ & $\underset{(603)}{M}$ & $\begin{array}{l}F \\
(203)\end{array}$ & $\underset{(806)}{M+F}$ & $\underset{(575)}{M}$ & $\begin{array}{l}F \\
(239)\end{array}$ & $\underset{(814)}{M}+F$ \\
\hline $\begin{array}{l}\text { Fatal stroke } \\
\text { Definite haemorrhage } \\
\text { Definite infarct } \\
\text { Uncertain pathology }\end{array}$ & $\begin{array}{l}3(0 \cdot 5) \\
4(0 \cdot 7) \\
5(0 \cdot 8)\end{array}$ & $\begin{array}{l}3(1.4) \\
2(0.9) \\
3(1.4)\end{array}$ & $\begin{array}{l}6(0 \cdot 7) \\
6(0 \cdot 7) \\
8(1 \cdot 0)\end{array}$ & $\begin{array}{l}2(0 \cdot 3) \\
3(0 \cdot 5) \\
8(1 \cdot 3)\end{array}$ & $\begin{array}{l}2(1 \cdot 0) \\
1(0 \cdot 5) \\
2(1 \cdot 0)\end{array}$ & $\begin{array}{r}4(0 \cdot 5) \\
4(0 \cdot 5) \\
10(1 \cdot 2)\end{array}$ & $\begin{array}{l}1(0 \cdot 2) \\
7(1 \cdot 2) \\
6(1 \cdot 0)\end{array}$ & $\begin{array}{l}0 \\
1(0 \cdot 4) \\
2(0 \cdot 8)\end{array}$ & $\begin{array}{l}1(0 \cdot 1) \\
8(1 \cdot 0) \\
8(1 \cdot 0)\end{array}$ \\
\hline $\begin{array}{l}\text { Fatal ischaemic heart disease (IHD } \\
\text { Myocardial infarction } \\
\text { Sudden, IHD at postmortem } \\
\text { Sudden, no postmortem } \\
\text { Other IHD }\end{array}$ & $\begin{array}{r}11(1 \cdot 8) \\
14(2 \cdot 3) \\
14(2 \cdot 3) \\
8(1 \cdot 3)\end{array}$ & $\begin{array}{l}4(1.9) \\
2(0.9) \\
1(0.5) \\
1(0.5)\end{array}$ & $\begin{array}{r}15(1 \cdot 8) \\
16(2 \cdot 0) \\
15(1 \cdot 8) \\
9(1 \cdot 1)\end{array}$ & $\begin{array}{r}12(2 \cdot 0) \\
17(2 \cdot 8) \\
9(1 \cdot 5) \\
7(1 \cdot 2)\end{array}$ & $\begin{array}{l}3(1 \cdot 5) \\
2(1 \cdot 0) \\
2(1 \cdot 0) \\
2(1 \cdot 0)\end{array}$ & $\begin{array}{r}15(1 \cdot 9) \\
19(2 \cdot 4) \\
11(1 \cdot 4) \\
9(1 \cdot 1)\end{array}$ & $\begin{array}{r}14(2 \cdot 4) \\
15(2 \cdot 6) \\
7(1 \cdot 2) \\
7(1 \cdot 2)\end{array}$ & $\begin{array}{l}1(0 \cdot 4) \\
4(1 \cdot 7) \\
4(1 \cdot 7) \\
2(0 \cdot 8)\end{array}$ & $\begin{array}{r}15(1 \cdot 8) \\
19(2 \cdot 3) \\
11(1 \cdot 4) \\
9(1 \cdot 1)\end{array}$ \\
\hline $\begin{array}{l}\text { Other vascular, excluding definitel } \\
\text { Ruptured aortic aneurysm } \\
\text { Other vascular, including }\end{array}$ & $1(0 \cdot 2)$ & $2(0 \cdot 9)$ & $3(0 \cdot 4)$ & $2(0 \cdot 3)$ & 0 & $2(0 \cdot 2)$ & $2(0 \cdot 3)$ & 0 & $2(0 \cdot 2)$ \\
\hline $\begin{array}{l}\text { gastrointestinal haemorrhage } \\
\text { Unknown }\end{array}$ & $\begin{array}{l}5(0 \cdot 8) \\
3(0 \cdot 5)\end{array}$ & $\begin{array}{l}2(0.9) \\
1(0.5)\end{array}$ & $\begin{array}{l}7(0.9) \\
4(0.5)\end{array}$ & $\begin{array}{l}7(1 \cdot 2) \\
4(0 \cdot 7)\end{array}$ & $\begin{array}{l}4(2 \cdot 0) \\
2(1 \cdot 0)\end{array}$ & $\begin{array}{r}11(1.4) \\
6(0.7)\end{array}$ & $\begin{array}{r}10(1 \cdot 7) \\
2(0 \cdot 3)\end{array}$ & $\begin{array}{l}0 \\
1(0 \cdot 4)\end{array}$ & $\begin{array}{r}10(1 \cdot 2) \\
3(0 \cdot 4)\end{array}$ \\
\hline Subtotal vascular deaths ${ }^{\star}$ & $68(11 \cdot 3)$ & $21(9 \cdot 8)$ & $89(10.9)$ & $71(11 \cdot 8)$ & $20(9.9)$ & $91(11 \cdot 3)$ & $71(12 \cdot 3)$ & $15(16 \cdot 3)$ & $86(10 \cdot 0)$ \\
\hline $\begin{array}{l}\text { Definitely non vascular deaths } \\
\text { Cancer } \\
\text { Other causes }\end{array}$ & $\begin{array}{r}9(1 \cdot 5) \\
10(1 \cdot 7)\end{array}$ & $\begin{array}{l}3(1 \cdot 4) \\
1(0 \cdot 5)\end{array}$ & $\begin{array}{l}12(1 \cdot 5) \\
11(1 \cdot 3)\end{array}$ & $\begin{array}{l}9(1 \cdot 5) \\
9(1 \cdot 5)\end{array}$ & $\begin{array}{l}\mathbf{0} \\
\mathbf{0}\end{array}$ & $\begin{array}{l}9(1 \cdot 1) \\
9(1 \cdot 1)\end{array}$ & $\begin{array}{l}17(3 \cdot 0) \\
10(1 \cdot 7)\end{array}$ & $\begin{array}{l}6(2 \cdot 5) \\
3(1 \cdot 3)\end{array}$ & $\begin{array}{l}23(2 \cdot 8) \\
13(1 \cdot 6)\end{array}$ \\
\hline Subtotal non vascular deaths & $19(3 \cdot 2)$ & $4(1.9)$ & $23(2 \cdot 8)$ & $18(3 \cdot 0)$ & 0 & $18(2 \cdot 2)$ & $27(4 \cdot 7)$ & $9(3 \cdot 8)$ & $36(4 \cdot 4)$ \\
\hline Total: all causes & $87(14 \cdot 5)$ & $25(11 \cdot 7)$ & $112(13 \cdot 7)$ & $89(14 \cdot 8)$ & $20(9 \cdot 9)$ & $109(13.5)$ & $98(17 \cdot 0)$ & $24(10.0)$ & $122(15 \cdot 0)$ \\
\hline
\end{tabular}

^Includes cerebrovascular, cardiovascular, other vascular, gastrointestinal haemorrhage and unknown causes.

|One non-vascular death was attributed to gastrointestinal ulceration (placebo group).

largest and statistically most significant effect of aspirin was a reduction in the odds of nonvascular death by $45 \%$ (95\% CI $11-66 \%$ odds reduction). This was largely due to a reduction in cancer deaths (table 12). However, because the overview ${ }^{2}$ showed no overall effect on nonvascular death we would not want to overemphasise this result which was responsible for a larger effect of aspirin on the originally planned analysis of "major stroke, myocardial infarction or death" (odds reduction 19\%, 95\% CI 3$32 \%$, that is, statistically significant) than on our analysis of "major stroke, myocardial infarction or vascular death" (odds reduction $15 \% ; 95 \%$ CI $29 \%$ odds reduction to $3 \%$ odds

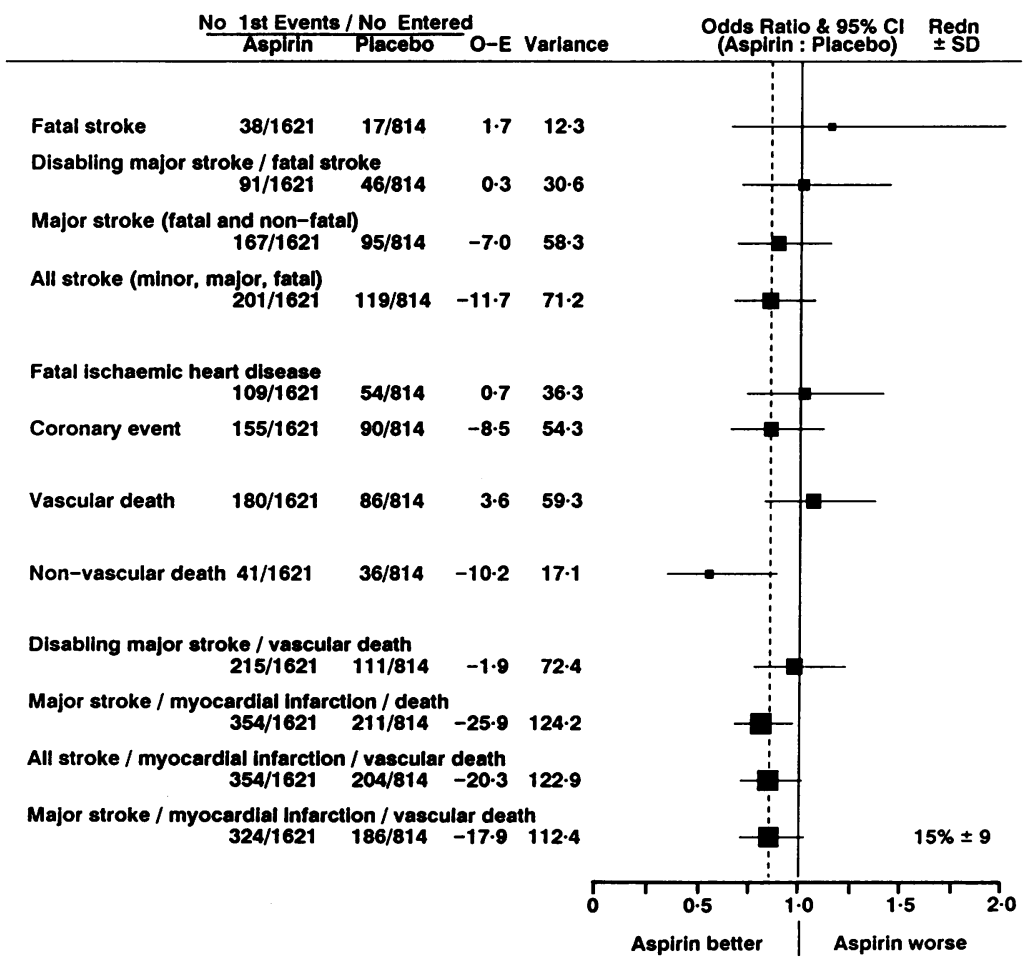

Figure 4 All patients; various types and combinations of stroke, myocardial infarction and death ("intention-to-treat" comparison of both aspirin groups together versus the placebo group). increase). There was almost no effect on "disabling major stroke and/or vascular death" nor on "vascular death" but the confidence intervals were very wide since the number of these more serious events was small. The effect of aspirin appeared within about three months and became more obvious over the next few months after which the survival curves of the aspirin and placebo groups remained more or less parallel (fig 5).

\section{"On-treatment" analysis}

This analysis is possibly subject to bias as we cannot be sure that the reasons for stopping trial medication were unrelated to the occurrence of an outcome event; it was also difficult to discover exactly when trial medication was stopped in individual patients, particularly if they had died suddenly. However, if patients were censored from the log rank analysis at the first follow up visit when their stated compliance was less than four ordinary trial tablets daily, or if medication prescribed was other than four ordinary trial tablets daily, we would have removed a large proportion of patients from the trial likely to have abandoned trial medication. Compared with the "intentionto-treat" analysis, the result of the "on-treatment" analysis for "major stroke, myocardial infarction or vascular death" was more in favour of aspirin; odds reduction $23 \%$ with standard deviation of $10 \%$.

\section{Subgroup analysis, both sexes combined}

Given the overall, non-statistically significant trend in favour of aspirin, from the point of view of "major stroke, myocardial infarction or vascular death" any subgroup analysis is unlikely to be reliable. However, with that proviso, there did not seem to be any definite difference in the effect of aspirin in males and females, older and younger patients, hypertensive and normotensive patients, and those with and without prior ischaemic heart disease. 
Table 13 Aspirin $300 \mathrm{mg}$ versus $1200 \mathrm{mg}$ daily: "intention to treat" comparison based on log rank survival analysis (Odds ratio < 1.0 when $1200 \mathrm{mg}$ daily more effective than $300 \mathrm{mg}$ daily)

\begin{tabular}{|c|c|c|c|}
\hline & Males & Females & Males and Females \\
\hline & $\begin{array}{l}\text { Odds ratio ( } 95 \% \\
\text { confidence interval) }\end{array}$ & $\begin{array}{l}\text { Odds ratio ( } 95 \% \\
\text { confidence interval) }\end{array}$ & $\begin{array}{l}\text { Odds ratio ( } 95 \% \\
\text { confidence interval) }\end{array}$ \\
\hline $\begin{array}{l}\text { Fatal stroke } \\
\text { Disabling major and/or fatal stroke } \\
\text { Major and/or fatal stroke } \\
\text { All strokes (minor, major, fatal) }\end{array}$ & $\begin{array}{l}0.96(0.44-2 \cdot 10) \\
1.04(0.63-1.72) \\
1.06(0.75-1.51) \\
1.04(0.76-1.43)\end{array}$ & $\begin{array}{l}1.58(0.53-4.69) \\
1.22(0.59-2.52) \\
1.08(0.59-1.98) \\
1.01(0.58-1.75)\end{array}$ & $\begin{array}{l}1.14(0.60-2.15) \\
1.09(0.73-1.65) \\
1.07(0.79-1.44) \\
1.03(0.78-1.36)\end{array}$ \\
\hline $\begin{array}{l}\text { Fatal ischaemic heart disease } \\
\text { Coronary event }\end{array}$ & $\begin{array}{l}1.10(0.73-1.65) \\
0.93(0.66-1.31)\end{array}$ & $\begin{array}{l}0.87(0.34-2.25) \\
1.06(0.49-2.33)\end{array}$ & $\begin{array}{l}1.06(0.73-1.54) \\
0.95(0.69-1.30)\end{array}$ \\
\hline $\begin{array}{l}\text { Vascular death } \\
\text { Non-vascular death }\end{array}$ & $\begin{array}{l}1.00(0.72-1 \cdot 40) \\
1 \cdot 10(0.58-2 \cdot 09)\end{array}$ & $\begin{array}{l}1.03(0.56-1.90) \\
7.48(1.05-53 \cdot 10)\end{array}$ & $\begin{array}{l}1.01(0.75-1.35) \\
1.32(0.72-2.44)\end{array}$ \\
\hline $\begin{array}{l}\text { Disabling major stroke/vascular death } \\
\text { Major stroke/myocardial infarction/death } \\
\text { All stroke/myocardial infarction/vascular death } \\
\text { Major stroke/myocardial infarction/vascular death }\end{array}$ & $\begin{array}{l}1.01(0.74-1.37) \\
0.99(0.79-1.25) \\
0.99(0.78-1.26) \\
0.99(0.78-1.27)\end{array}$ & $\begin{array}{l}1 \cdot 24(0 \cdot 72-2 \cdot 14) \\
1 \cdot 27(0 \cdot 80-2 \cdot 00) \\
1 \cdot 11(0 \cdot 71-1 \cdot 72) \\
1 \cdot 20(0 \cdot 76-1 \cdot 92)\end{array}$ & $\begin{array}{l}1.06(0.81-1.38) \\
1.04(0.85-1.29) \\
1.02(0.82-1.25) \\
1.03(0.83-1.29)\end{array}$ \\
\hline
\end{tabular}

Table 14 Placebo versus aspirin ("high dose" and "low dose" groups combined) : "intention-to-treat" comparison based on log rank survival analysis (Odds ratio $<1.0$ when aspirin more effective than placebo)

\begin{tabular}{|c|c|c|c|}
\hline & Males & Females & Males and Females \\
\hline & Odds ratio $(95 \%$ CI) & Odds ratio ( $95 \% \mathrm{CI})$ & Odds ratio ( $95 \%$ CI) \\
\hline $\begin{array}{l}\text { Fatal stroke } \\
\text { Disabling major and/or fatal stroke } \\
\text { Major and/or fatal stroke } \\
\text { All strokes (minor, major, fatal) }\end{array}$ & $\begin{array}{l}0.87(0.44-1.69) \\
0.80(0.53-1.22) \\
0.89(0.66-1.21) \\
0.86(0.65-1.13)\end{array}$ & $\begin{array}{l}2.19(0.79-6.04) \\
1.79(0.93-3.46) \\
0.87(0.53-1.41) \\
0.82(0.53-1.27)\end{array}$ & $\begin{array}{l}1 \cdot 15(0.66-2 \cdot 01) \\
1.01(0.71-1 \cdot 44) \\
0.89(0.69-1 \cdot 15) \\
0.85(0.67-1 \cdot 07)\end{array}$ \\
\hline $\begin{array}{l}\text { Fatal ischaemic heart disease } \\
\text { Coronary event }\end{array}$ & $\begin{array}{l}1.05(0.73-1.51) \\
0.85(0.63-1.13)\end{array}$ & $\begin{array}{l}0.88(0.40-1.89) \\
0.89(0.47-1.69)\end{array}$ & $\begin{array}{l}1.02(0.74-1.41) \\
0.85(0.66-1.12)\end{array}$ \\
\hline $\begin{array}{l}\text { Vascular death } \\
\text { Non-vascular death }\end{array}$ & $\begin{array}{l}0.95(0.72-1.27) \\
0.66(0.39-1.11)\end{array}$ & $\begin{array}{l}1.56(0.91-2.68) \\
0.24(0.08-0.74)\end{array}$ & $\begin{array}{l}1.06(0.82-1.37) \\
0.55(0.34-0.89)\end{array}$ \\
\hline $\begin{array}{l}\text { Disabling major stroke/vascular death } \\
\text { Major stroke/myocardial infarction/death } \\
\text { All stroke/myocardial infarction/vascular death } \\
\text { Major stroke/myocardial infarction/vascular death }\end{array}$ & $\begin{array}{l}0.85(0.65-1.10) \\
0.78(0.64-0.95) \\
0.81(0.66-0.99) \\
0.80(0.65-0.99)\end{array}$ & $\begin{array}{l}1.56(0.97-2.53) \\
0.94(0.64-1.36) \\
1.00(0.70-1.44) \\
1.06(0.72-1.56)\end{array}$ & $\begin{array}{l}0.97(0.77-1.23) \\
0.81(0.68-0.97) \\
0.85(0.71-1.01) \\
0.85(0.71-1.03)\end{array}$ \\
\hline
\end{tabular}

Intracranial haemorrhage

We were able to reliably differentiate cerebral infarction from intracerebral haemorrhage on the basis of early CT or necropsy examination in about half of the strokes during follow up. Although we recorded 16 intracranial haemorrhages, this was probably an underestimate of the true number. However, this would not have biased the relative difference between the three treatment groups. We recorded seven intracranial haemorrhages in the "high-dose" group, seven in the "low-dose" group, and two in the "placebo" group. The numbers are small but do represent about a three times excess risk in those allocated aspirin although this was not statistically significant.

\section{Discussion}

This trial showed a strong trend in favour of aspirin reducing the risk of major stroke,

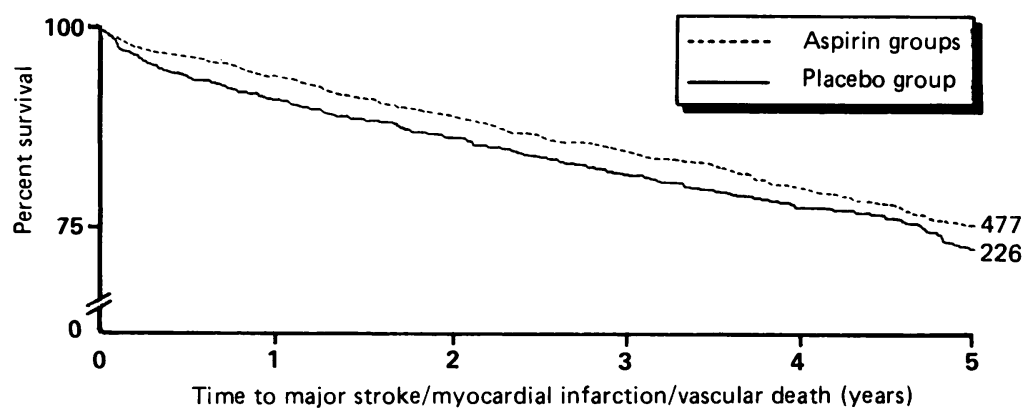

Figure 5 Survival curves comparing both aspirin groups together in both sexes with the placebo group in both sexes. Non-vascular deaths have been censored so that the $y$-axis refers to survival free of "major stroke, myocardial infarction or vascular death". After five years there were 477 aspirin allocated and 226 placebo allocated patients who were still alive and had not had a major stroke or myocardial infarction. myocardial infarction and vascular death and a very weak trend in favour of reducing the risk of disabling stroke and vascular death. Vascular death was slightly more frequent in the aspirin groups, but the confidence interval was large. If this was the only trial of aspirin available there would be a clear need to repeat it with larger numbers so that a more precise estimate of the effect of aspirin could be achieved. There would also be no indication for aspirin in routine clinical practice. There are, however, several similar trials. Our results should therefore be seen in the context of all other similar unconfounded trials of aspirin and alternative antiplatelet regimes in an overview (or meta) analysis, the first phase of which has been published by the Antiplatelet Trialists' Collaborative Group. ${ }^{2}$ Our results are entirely consistent with this overview although, by chance, we overestimated the effect of aspirin on non-vascular death and underestimated the effect on all stroke, myocardial infarction or vascular death; these chance effects are hardly surprising given our sample size of 2435 compared with the much larger number of 29073 randomised patients available for the overview analysis. In retrospect, we overestimated the number of vascular events we expected in the placebo group; about $10 \%$ per annum of all stroke, myocardial infarction or vascular death compared with about $6 \%$ per annum observed. Also, we may well have randomised some patients after the particularly high risk period for stroke during the first few weeks after TIA, ${ }^{8}$ so reducing our stroke rate still further. Given the limitations in research funding and the length of time considered reasonable to continue randomising patients, we were unable to recruit enough patients; again, in retrospect, 
we should have sought wider collaboration not just in the UK, but also in Europe.

Although somewhat imprecise, the trial results are unbiased by any important baseline inequality between the three groups of patients and by any knowledge of the treatment allocation of individual patients during follow up and assessment of the events analysed. Although there were more complaints of upper gastrointestinal symptoms from those subjects taking aspirin (than those on placebo), the difference was not so great that it would have affected the "blinding" of either patients or collaborating neurologists. In any event, the clinical audit committee had no knowledge of any adverse effects when examining the validity of the analysable events in individual patients.

This trial is the only one to have compared directly $1200 \mathrm{mg}$ with $300 \mathrm{mg}$ daily of aspirin. There can be no doubt that the higher dose was more gastrotoxic, producing mild but irritating upper gastrointestinal symptoms and almost certainly gastrointestinal haemorrhage as well. Presumably dispersible, soluble, or enteric coated aspirin $300 \mathrm{mg}$ daily would have caused less than the approximate $19 \%$ increase in mild gastric adverse effects, and the two to three fold increase in the risk of gastrointestinal haemorrhage that we observed compared with placebo. Given the reversibility of the mild adverse effects and the very low mortality and negligible long term morbidity of gastrointestinal haemorrhage, this seems a small price to pay for the approximate $25 \%$ reduction in the risk of serious vascular events evident from the overview analysis. ${ }^{2}$ There was no obvious dose response relationship for constipation and bruising, nor for intracranial haemorrhage. Whether aspirin definitely causes or precipitates intracranial haemorrhage is a question that will only be answered reliably from the next phase of the overview analysis rather than on the basis of the small numbers reported here.

If doses lower than $300 \mathrm{mg}$ daily of aspirin are shown to be as effective, then maybe the risk-benefit balance would be even more in favour of aspirin; the cost is already so low that it is almost not worth considering (approximately $£ 1.46$ per annum for $300 \mathrm{mg}$ soluble aspirin daily, according to the British National Formulary).

We believe that the results of this trial, and other similar unconfounded trials included in the Antiplatelet Trialists' Collaboration overview, can be generalised to individual patients with transient ischaemic attacks, mild ischaemic strokes, and possibly more major ischaemic strokes. This is because qualitatively, all are similar in terms of their underlying arterial pathology; most patients have atheroma but a small proportion have an embolic source in the heart. For the latter it may eventually transpire that anticoagulation with warfarin is more effective than aspirin.

It may be reasonable to start aspirin treatment as soon as patients present to medical attention, but whether it is safe to do so in a stroke patient before intracerebral haemorrhage is excluded by an early CT scan is uncertain. However, there is no doubt that this question could and should be answered in a large scale trial of aspirin, not for secondary prevention but for the treatment of acute stroke within hours of onset. Naturally, for any individual transient ischaemic attack or stroke patient it is impossible to know exactly what the risk of a future serious vascular event will be and exactly how much the risk will be reduced by aspirin. However, on balance, the effect of aspirin is likely to be favourable, provided it is avoided in patients with obvious contraindications, such as, an active peptic ulcer.

This manuscript was prepared by B Farrell, J Godwin, S Richards and $\mathrm{C} W$ arlow.

We thank the Medical Research Council for their support and also Beecham Products, Eli Lilly, Evans Medical/Glaxo, Wasell Packaging, and the Aspirin Foundation for their help. We are also extremely grateful for the help we received from the pharmacists, clinical chemists and chemical pathologists in the pharmacists, clinical chemists and chemical pathologists in the collaborating centres. The trial was designed, executed and
analysed completely independently of any and all sponsoring organisations.

1 UK-TIA Study Group. United Kingdom transient ischaemic attack (UK-TIA) aspirin trial: interim results. BMJ 1988;296:316-20.

2 Antiplatelet Trialists' Collaboration. Secondary prevention of vascular disease by prolonged antiplatelet treatment. of vascular disease by

3 Peto R, Pike MC, Armitage $P$, et al. Design and analysis of randomised clinical trials requiring prolonged observation randomised clinical trials requiring prolonged

4 Skegg DGG, Doll R. Record linkage for drug monitoring. $J$ Epidem Comm Health 1981;35:25-31

5 Yusuf S, Peto R, Lewis J, Collins R, Sleight P. Beta blockade during and after myocardial infarction: an overview of the randomised trials. Prog Cardiovasc Dis 1985;27:335-71.

6 Rankin J. Cerebral vascular accidents in people over the age of 60. II. Prognosis. Scot Med J 1957;2:200-15.

7 Patrono C, Ciabattoni G, Patrignani P, et al. Clinical pharmacology of platelet cycloxygenase inhibition. Circulation 1985;72:1177-84.

8 Dennis M, Bamford J, Sandercock P, Warlow C. The prognosis of transient ischaemic attacks in the Oxfordshire prognosis of transient ischaemic attacks in the Oxfordshi
Community Stroke Project. Stroke 1990;21:848-53. 